\title{
Autoimmunity in connection with a metal implant: a case of autoimmune/autoinflammatory syndrome induced by adjuvants
}

\author{
Esthela Loyo $\cdot$ Luis J. Jara • Persio David López • \\ Ana Carolina Puig
}

Received: 1 July 2012/ Accepted: 26 November 2012/Published online: 15 December 2012

(C) Springer-Verlag Italia 2012

\begin{abstract}
Autoimmune/autoinflammatory syndrome induced by adjuvants (ASIA) has been recently proposed by Shoenfeld and Agmon-Levin as a new entity that comprises several conditions: the macrophagic-myofasciitis syndrome, the Gulf War syndrome, silicosis and postvaccination phenomena, autoimmunity related to infectious fragments, hormones, aluminum, silicone, squalene oil, and pristane. We report the case of a 23-year-old woman who developed serial episodes of high fever, extreme fatigue, transient thrombocytopenia, multiple cervical adenopathies, hepatosplenomegaly, anemia, neutropenia, severe proteinuria and urine sediment abnormalities, elevated serum ferritin levels, and transient low positive antinuclear antibodies 1 year after she had a nickel-titanium chin implant for cosmetic reasons. The clinical picture simulated a variety of probable diseases: systemic lupus erythematosus, Kikuchi-Fujimoto syndrome, adult onset Still's disease, antiphospholipid syndrome, and hemophagocytic syndrome, among others, so she underwent an extensive medical investigation including two lymph node biopsies. She received treatment accordingly with steroids, methotrexate, and mofetil mycophenolate, with initial improvement of her symptoms, which recurred every time the dose
\end{abstract}

\section{E. Loyo ( $\square)$}

Head, Rheumatology and Clinical Immunology Department, Hospital Regional Universitario José Ma. Cabral y Báez,

Santiago, Dominican Republic

e-mail: esthela.loyo@gmail.com

\section{J. Jara}

Hospital de Especialidades "Dr. Antonio Fraga Mouret" Centro

Médico Nacional La Raza, IMSS, Mexico, DF, Mexico

P. D. López · A. C. Puig

Pontificia Universidad Católica Madre y Maestra,

Santiago, Dominican Republic was reduced. Two and a half years later the patient decided to retire the chin implant and afterwards all her systemic symptoms have disappeared. She remains in good health, without recurrence of any symptom and off medications until today. Albeit this patient fulfills proposed major ASIA criteria, to our knowledge it would be the first description of systemic features of autoinflammation in connection with a metal implant.

Keywords Adult onset Still's disease - Lupus-like syndrome $\cdot$ ASIA syndrome $\cdot$ Metal hypersensitivity

\section{Introduction}

Autoimmune (autoinflammatory) syndrome induced by adjuvants (ASIA) denotes a complex of signs and symptoms that suggest a "direct link between injection of foreign matter and 'autoimmune'-like syndromes" [1-3].

Adjuvants have been widely used in medicine as a tool to increase desired immune responses against certain microbes, i.e., vaccination. However, these substances can also increase the immune responses elicited to undesired levels, as vaccines can induce autoantibodies and manifestations of arthritis, encephalitis, and even vasculitis [4]. The risks factors are unknown.

In the last decade, there has been a concern about possible allergic (hypersensitivity) reactions to foreign materials implanted in the body. The most common form of metal hypersensitivity is contact dermatitis due to nickel [5], which has led the Northern European countries to regulate consumer nickel exposure. Consumer items intended to be in direct and prolonged contact with the skin are not allowed to release more than $0.5 \mu \mathrm{g}$ nickel $/ \mathrm{cm}^{2} /$ week [6]. However, the metal use in oral, cardiovascular, 
orthopedic, and now cosmetic devices continues to increase over time, with little control at all.

We report the case of a young female who developed severe systemic autoinflammatory manifestations 1 year after a cosmetic nickel-titanium chin implant, all of which resolved after the implant was retired.

\section{Case report}

While in Argentina as an Odontology student in November 2006, a 23-year-old female started with high fever, extreme fatigue, cervical adenopathies, and transient thrombocytopenia. At the time she was diagnosed with dengue fever; a lymph node biopsy reported 'reactive hyperplasia' only.

She also presented splenomegaly and urine sediment alterations with protein and granular cylinders, which were attributed to the fever.

As a child, she suffered repeated respiratory allergic reactions and several bouts of allergic asthma. Her mother related an episode of cutaneous hypersensitivity to an oral anti-inflammatory drug (fixed pigmented erythema apparently against diclofenac). At the age of 19, the patient underwent eye surgery for myopic correction and an abdominal liposuction. Approximately, 1 year before all symptoms began in Argentina, she had a nickel-titanium chin implant for cosmetic reasons.

First visit and treatment

The patient was brought to Dominican Republic in May 2007 because of a new episode of high fever $\left(40{ }^{\circ} \mathrm{C}\right.$, documented), extreme fatigue and general malaise, multiple bilateral cervical adenopathies, and hepatosplenomegaly. Initial laboratory results revealed anemia (hemoglobin $8.1 \mathrm{~g} / \mathrm{dL}$ ), leucopenia (WBC count 2,500 cells $/ \mathrm{mm}^{3}$ ) and platelets $150,000 \mathrm{~mm}^{3}$, positive anti-nuclear antibodies (ANA) 1:40 with a speckled pattern, and elevation in hepatic enzymes (AST $94 \mathrm{IU} / \mathrm{L}$, ALT 33 IU/L), and LDH 1,357 IU/L. Further workup is detailed in Table 1.

Subsequent analysis determined a negative rheumatoid factor (RF), negative anti-citrullinated peptide antibodies (ACPA) along with negative results in new ANA, anti-Ro, -Sm, and -dsDNA determinations, and normal IgE levels. C3 levels were $135 \mathrm{mg} / \mathrm{dL}$ ( $88-206 \mathrm{mg} / \mathrm{dL}$ ), while C4 was $16 \mathrm{mg} / \mathrm{dL}(13-75 \mathrm{mg} / \mathrm{dL})$. All her cultures and bacilloscopies were negative too, as well as a virus panel testing (HIV1/2, hepatitis B and C, cytomegalovirus, Epstein-Barr and herpes simplex 1/2) and serum tests for syphilis. Thorax $\mathrm{X}$-rays were normal but a transthoracic echocardiogram revealed fluid in the pericardium with a $75 \%$ ejection fraction, without evidence of endocarditis. A second lymph node biopsy again reported 'reactive hyperplasia.'
Other departments (hematology, infectivology) were involved in the evaluation and workup, but there was no definitive diagnosis. We began treatment with intra-venous (IV) methylprednisolone, and she had a rapid good clinical response and eventual remission of symptoms.

Second visit and treatment

Back in Argentina, where she was referred to a rheumatologist, she was diagnosed as adult onset Still's disease (AOSD) because of elevated ferritin serum levels and started on oral methotrexate $10 \mathrm{mg}$ once a week and decreasing doses of oral steroids. However, she did not feel well and in April 2008 returned to the Dominican Republic with a similar clinical picture as in 2007: fever, myalgia, arthralgia, anemia, and high ferritin $(1,500 \mathrm{ng} / \mathrm{mL})$; ANA and anti-dsDNA antibodies were negative, C3 and C4 were normal. She had negative anti-cardiolipin antibodies (IgG, IgM, and $\operatorname{IgA}$ ). She improved with prednisone $30 \mathrm{mg} /$ day and was switched to subcutaneous methotrexate $20 \mathrm{mg} /$ week.

Alas, her improvement did not last. She presented again in June with anemia, myalgia, arthralgia, ferritin $1,970 \mathrm{ng} / \mathrm{ml}$, and elevated hepatic enzymes for the third time, as a result of lowering the dose of prednisone to $10 \mathrm{mg} /$ day. In September 2008, we withdrew methotrexate due to lack of response and started mofetil mycophenolate $2.0 \mathrm{~g} /$ day. Ferritin level dropped to $58 \mathrm{ng} / \mathrm{ml}$ and ESR to $9 \mathrm{~mm} / \mathrm{h}$. She did well throughout 2009, but was lost to follow-up, returning in January 2010 with severe abdominal pain and acute splenomegaly, high fever, transient cutaneous rash, arthralgia, anemia, massive proteinuria $(3,407 \mathrm{mg} / 24 \mathrm{~h})$ with granular and hyaline cylinders, ferritin $1,270 \mathrm{ng} / \mathrm{mL}$, ESR $50 \mathrm{~mm} / \mathrm{h}$, negative ANA and anti-dsDNA, negative anti-cardiolipin and anti-beta-2-glycoprotein antibodies, and normal C3 and C4. The patient had suspended her medications. Again, the clinical picture abated with prednisone $60 \mathrm{mg} /$ day.

\section{Solution}

At the end of January 2010, the patient opted for removal of the nickel-titanium implant, assuming it was responsible for her symptoms, since they had began after the implant. Her clinical picture actually improved and 3 months later she was off steroids and mycophenolate. In her most recent follow-up, June 2012, she was clinically asymptomatic; all her laboratory studies were normal [including ferritin $(25.6 \mathrm{ng} / \mathrm{mL})$ ].

\section{Discussion}

This case highlights the inherent difficulties encountered in daily practice regarding autoimmunity diseases. Before the 
Table 1 Further workup on presentation

\begin{tabular}{llll}
\hline Test & Initial results & Evolution & $\begin{array}{l}\text { Normal } \\
\text { range }\end{array}$ \\
\hline Ferritin & $>2,000$ & $>1,500$ & $6-159 \mathrm{ng} / \mathrm{mL}$ \\
C reactive protein & 78 & 80 & $1.0-3.0 \mathrm{mg} / \mathrm{dL}$ \\
Erythrosedimentation rate & 30 & 50 & $<20 \mathrm{~mm} / \mathrm{h}$ \\
Anti-nuclear antibodies & $1: 40$ with a speckled pattern & Negative & - \\
Anti-dsDNA & Negative & Negative & - \\
Anti-SSA/SSB (Ro/La) & Negative & Negative & - \\
Anti-Sm & Negative & Negative & - \\
Anti-RNP & & Negative & \\
Anti-Scl70 & & Negative & - \\
Rheumatoid factor & Negative & Negative & - \\
ACPA & Negative & Negative & - \\
aCL-IgG, IgM, IgA & & Negative & - \\
B-2-glycoprotein IgG, & & Negative & \\
IgM, IgA & & & $88-206 \mathrm{mg} / \mathrm{dL}$ \\
C3 & 135 & 112 & $13-75 \mathrm{mg} / \mathrm{dL}$ \\
C4 & 16 & 26 & - \\
Urinalysis & Protein 3+; granular cylinders $2+$ & Protein 3+; granular & - \\
& & and hyaline & \\
Protein urine test $(24 \mathrm{~h})$ & 2,378 & cylinders & \\
\hline
\end{tabular}

nickel-titanium chin implant, this patient had a normal life, with an unremarkable history of allergies to common household items during infancy. Her debut with severe malaise, high fever, visceromegaly and multiple adenopathies plus positive ANA, high serum ferritin levels, and all the signs and symptoms described pointed to a severe clinical immune dysfunction. However, the whole clinical and serological picture abated after the implant surgical excision.

\section{Differential diagnosis}

In most patients, AOSD is characterized by four cardinal symptoms: spiking fever, an evanescent salmon-pink maculopapular rash, arthritis, and elevated white blood cells, mainly neutrophils [7]. Other features, as sore throat, myalgia, lymph node or spleen enlargement, pleuritis, pericarditis, elevated levels of liver enzymes, and other hematologic disturbances, have been described. None of these features is specific and as a consequence AOSD is an exclusion diagnosis [8].

Initially, this patient seemed to fall into a polycyclic pattern of AOSD. However, though her high serum ferritin levels suggested AOSD, she did not fulfill major Yamaguchi criteria [9] (i.e., she had leucopenia instead of leucocytosis and also had rare features like renal involvement). There was no evidence of infection, malignant, or hemophagocytic disease. No signs of vasculitis and no true muscular weakness either. The lack of synovitis, negative RF, and ACPA helped to rule out the rheumatoid arthritis. The combination of pericarditis, arthralgia, renal involvement, anemia, and leucopenia in addition to transient thrombocytopenia suggested systemic lupus erythematosus, but the repeated negative ANA, anti-dsDNA and anti-Sm tests, and normal complement levels did not support the diagnosis. She also had repeated negative antiphospholipid serum profile.

Final diagnosis

According to the criteria proposed by Shoenfeld and Agmon-Levin [2] for the diagnosis of the ASIA syndrome (Table 2), this patient had all four major ones (Table 3) and also one very important minor (a lupus-like syndrome and/or atypical AOSD), as has been already described [10].

Nickel and immune response

Environmental factors, such as chemicals, infectious agents, or drugs, have been implicated in the expression of autoimmune diseases. Recent findings conclude that crystalline silica, solvent, smoking, and ultraviolet radiation exposure can contribute to the generation of autoimmune disease [11]. Nickel is a ubiquitous trace element, and is the fourth most frequently used metal in the world and the 
Table 2 Suggested criteria for ASIA diagnosis

\begin{tabular}{|c|c|}
\hline Major criteria & Minor criteria \\
\hline $\begin{array}{l}\text { Exposure to an external stimulus } \\
\text { (infection, vaccine, silicone, } \\
\text { adjuvant) prior to clinical } \\
\text { manifestations. }\end{array}$ & $\begin{array}{l}\text { Appearance of autoantibodies or } \\
\text { antibodies directed at the } \\
\text { suspected adjuvant. }\end{array}$ \\
\hline $\begin{array}{l}\text { Appearance of one of the clinical } \\
\text { manifestations listed below: } \\
\text { myalgia, myositis, or muscular } \\
\text { weakness. Arthralgia and/or } \\
\text { arthritis. Chronic fatigue, non- } \\
\text { restful sleeps, or sleep } \\
\text { disturbances. Neurological } \\
\text { manifestations (especially those } \\
\text { associated with demyelination), } \\
\text { cognitive impairment, memory } \\
\text { loss. Pyrexia. Dry mouth. }\end{array}$ & $\begin{array}{l}\text { Other clinical manifestations } \\
\text { (i.e., irritable bowel syndrome). }\end{array}$ \\
\hline $\begin{array}{l}\text { Removal of inciting agent } \\
\text { induces improvement. }\end{array}$ & $\begin{array}{l}\text { Specific HLA (i.e., HLA DRB1, } \\
\text { HLA DQB1) }\end{array}$ \\
\hline $\begin{array}{l}\text { Typical biopsy of involved } \\
\text { organs. }\end{array}$ & $\begin{array}{l}\text { Evolvement of an autoimmune } \\
\text { disease (i.e., multiple sclerosis, } \\
\text { systemic sclerosis). }\end{array}$ \\
\hline \multicolumn{2}{|c|}{$\begin{array}{l}\text { There must be the presence of at least two major or one major and } \\
\text { two minor criteria. }\end{array}$} \\
\hline \multicolumn{2}{|c|}{ From Shoenfeld and Agmon-Levin [1] } \\
\hline Table 3 Fulfillment of ASIA cri & \\
\hline Major/minor criteria & Our case \\
\hline $\begin{array}{l}\text { Exposure to an external stimulus } \\
\text { prior to clinical manifestations. }\end{array}$ & $\begin{array}{l}\text { Nickel-titanium chin implant } \\
1 \text { year before symptoms } \\
\text { began. }\end{array}$ \\
\hline Clinical manifestations. & $\begin{array}{l}\text { Myalgia, arthralgia, pyrexia, and } \\
\text { extreme fatigue. }\end{array}$ \\
\hline $\begin{array}{l}\text { Typical biopsy of involved } \\
\text { organs. }\end{array}$ & $\begin{array}{l}\text { 'Reactive hyperplasia' on two } \\
\text { lymphadenopathy biopsies. }\end{array}$ \\
\hline $\begin{array}{l}\text { Removal of inciting agent induces } \\
\text { improvement. }\end{array}$ & $\begin{array}{l}\text { Yes. Since January } 2010 \text { until } \\
\text { today. }\end{array}$ \\
\hline $\begin{array}{l}\text { Evolvement of an autoimmune } \\
\text { disease. }\end{array}$ & $\begin{array}{l}\text { Multiple clinical systemic } \\
\text { features plus serologic } \\
\text { evidence of inflammation. }\end{array}$ \\
\hline
\end{tabular}

From Shoenfeld and Agmon-Levin [1]

principle cause of allergic contact dermatitis (ACD). Cobalt, chromium, molybdenum, and gold are less often implicated [5]. Nickel is found in many commercial products (zippers, buttons, jewelry, watches, eye glass frames, and mobile phones) and many of these items have been linked to ACD, a delayed-type hypersensitivity reaction, which characteristically does not involve immediate allergic reactions, systemic features, or escalate to anaphylaxis.

Data supporting association of nickel with autoimmune disease are scarce. Experimental rat models have demonstrated positivity of serum ANA after both oral and subcutaneous nickel administration, with development of sclerodermic features on the skin being more prominent when the subcutaneous route was used $[12,13]$. Others had demonstrated that the parenteral administration of nickel produces greater metal accumulation in the lung, denoted by hydropic and degenerative changes of the endothelium of pulmonary arteries and veins, marked proliferation of alveolar lining cells and thickening of alveolar walls, and hyperplasia of bronchial epithelium [14]. In Norway rats, parenteral administration of nickel chloride can induce morphological and biochemical signs of alveolar macrophage activation, with nickel deposition both in tissue and macrophage cytoplasm even after a single dose [15]. It seems that depending on the nature of contact with nickel ions, as well as length and intensity of exposition and the administration route, this could produce allergy in susceptible individuals.

\section{Nickel and human experience}

Contact dermatitis is caused by $\mathrm{CD} 8^{+}$and $\mathrm{CD} 4^{+} \mathrm{T}$ cells mediated delayed hypersensitivity reaction to haptenmodified MHC-peptide complexes [16], both haptenbound and hapten-free $[12,16]$. Soluble derivatives of the metal are formed due to its ready oxidation by skin exudates, which deposit in the stratum corneum, potentially diffusing further to reach the epidermal cells: keratinocytes, lymphocytes, and Langerhans cells [17]. Itching and general symptoms such as headache, nausea, and malaise have been reported after oral nickel exposure in previously known sensitive individuals. Systemic contact dermatitis is seen when sensitized individuals are exposed to a hapten systemically [18], a condition now described as systemic nickel allergy syndrome (SNAS), a nickel-related proinflammatory status [19] with generalized cutaneous signs and symptoms. Interestingly, there is one report of a patient with a systemic non-cutaneous reaction to nitinol, an alloy composed of nickel $(55 \%)$ and titanium $(45 \%)$ used in percutaneous patent foramen ovale occluders. This patient was a female with a significant history for allergic reactions to some medications and an episode of allergic asthma. The patient began having dyspnea, fever $\left(38^{\circ} \mathrm{C}\right)$ and dependent edema that only resolved after explantation of the occluder, which led to the presumptive diagnosis of 'hypersensitivity to the device' [20]. Pathologic examination showed only non-specific inflammation. In humans, freshly isolated nickel-reactive $\mathrm{T}$ cells have been characterized as $\mathrm{CD} 4^{+}$ $\mathrm{CLA}^{+}$memory $\mathrm{T}$ cells which express the chemokine receptors CXCR3, CCR4, and CCR10 [21]. This profile denotes an activated $T$ cell status migrating from peripheral blood to the sites of skin inflammation, and supports the idea that small water-soluble molecules such as nickel are 
Fig. 1 Amplification of the immune response. Persistent exposition to nickel ions or its derivatives is capable of

(1) macrophage activation and

(2) antigen presentation in the context of MHC class II molecules to $\mathrm{CD} 4^{+} \mathrm{T}$ cells. Repeated exposure might trigger preferential $\mathrm{T}_{\mathrm{H}} 2$-driven inflammation

\section{Genetically susceptible host}

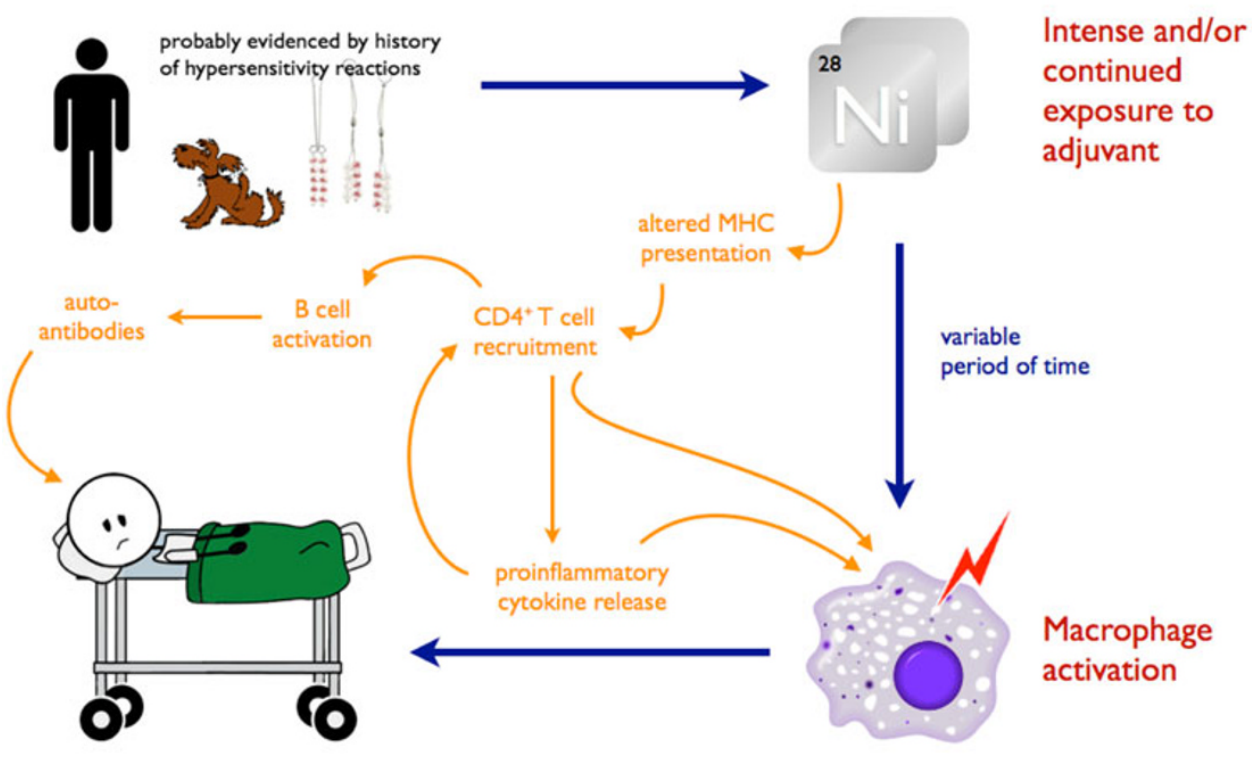

Autoimmune/ autoinflammatory disease preferentially presented in the context of MHC class II molecules to $\mathrm{CD} 4^{+} \mathrm{T}$ cells and this, in turn, might contribute to the amplification of the immune response (Fig. 1). It seems that a short-term, high level exposure to a metal derivative as hapten can result in selective $\mathrm{T}_{\mathrm{H}} 1$-driven inflammation, whereas more prolonged and repeated exposure to the same molecule might favor preferential $\mathrm{T}_{\mathrm{H}}$ 2-driven inflammation instead [22], and increased susceptibility to allergic disease in the context of genetic predisposition. Increased susceptibility to sensitization may be acquired or may be increased due to a high induction dose of the allergen if exposure exceeds the individual threshold [23, 24]. In our patient, prolonged exposure to a prosthesis containing nickel and titanium could have triggered the symptoms of systemic autoinflammation, which responded to corticosteroids. The patient we presented had florid systemic features of inflammation for at least 2.5 years, until the excision of her metal implant. Due to our limitations, we did not have the availability of doing a skin patch test for nickel or titanium sensibility, and we did not have the pathologic examination of the implant.

Two lymph node biopsies only reported reactive hyperplasia, but no immunohistochemical studies were done. Though further studies are needed, it seems that nickel is capable of macrophage activation beyond the alveolar space in genetically susceptible individuals, in a way that resembles macrophage activation in response to aluminum adjuvant in the macrophagic-myofasciitis syndrome [25]. Other monocyte-derived cells could carry nickel particles to secondary lymphoid tissues, including the spleen, and provoke further $\mathrm{T}$ cell recruitment.

\section{Conclusions}

The remarkable clinical course that finally resolved with removal of the device led us to consider ASIA syndrome, probably the first description of systemic features of autoinflammation in connection with a metal implant. Systemic reactions might not be common, but the potential risk of nickel or the nickel-titanium combination toxicity should not be ignored [26], especially in the context of a personal clinical history suggestive of allergies in susceptible individuals. It may be relevant to assess immunological functions of patients with an implant or in close contact with a nickel-releasing material prior and post-nickel exposure [11], since a large part of the general population tests positive to skin patch testing with nickel sulfate yet remains asymptomatic, and conversely, many who complain of metal intolerance test negative [16].

We suggest better regulatory control of metal exposure [27] and be alert to the possibility of adverse autoimmune/autoinflammatory signs and symptoms compatible with ASIA syndrome and the need of a high index of suspicion.

Conflict of interest None. 


\section{References}

1. Shoenfeld Y, Agmon-Levin N (2011) "ASIA"-Autoimmune/ inflammatory syndrome induced by adjuvants. J Autoimmun 36: 4-8

2. Agmon-Levin N, Hughes G, Shoenfeld Y (2012) The spectrum of ASIA: 'autoimmune (autoinflammatory) syndrome induced by adjuvants'. Lupus 21:118-120

3. Hughes GRV (2012) Foreword. Lupus 21:117

4. Agmon-Levin N, Paz Z, Israeli E, Shoenfeld Y (2009) Vaccines and autoimmunity. Nat Clin Pract Rheum 5(11):648-652

5. Thyssen JP, Menné T (2010) Metal allergy-a review on exposures, penetration, genetics, prevalence, and clinical implications. Chem Res Toxicol 23:309

6. Thyssen JP, Uter W, McFadden J, Menné T, Spiewak R, Vigan M et al (2011) The EU Nickel Directive revisited -future steps towards better protection against nickel allergy. Contact Dermatitis 64:121-125

7. Fautrei B (2008) Adult-onset Still's disease. Best Pract Res Clin Rheum 22:773-792

8. Bagnari V, Colina M, Ciando G et al (2010) Adult-onset Still's disease. Rheumatol Int 7:855-862

9. Yamaguchi M, Ohta A, Tsunematsu T et al (1992) Preliminary criteria for classification of adult Still's disease. J Rheumatol 19:424-430

10. Jara LJ, Medina G, Gómez-Bañuelos E, Saavedra M, Vera-Lastra O (2012) Still's disease, lupus-like syndrome, and silicone breast implants. A case of 'ASIA' (Shoenfeld's syndrome). Lupus 21(2):140-145

11. Miller FW, Alfredsson L, Costenbander KH et al (2012) Epidemiology of environmental exposures and human autoimmune diseases: findings from a National Institute of Environmental Health Sciences Expert Panel Workshop. J Autoimmun 39(4): 259-271

12. Al-Mogairen SM, Meo SA, Al-Arfaj AS et al (2010) Nickelinduced allergy and contact dermatitis: does it induce autoimmunity and cutaneous sclerosis? An experimental study in Brown Norway rats. Rheumatol Int 30:1159-1164

13. Al-Mogairen S (2010) Induction of autoimmunity in Brown Norway rats by oral and parenteral administration of nickel chloride. Lupus 19:262-267
14. Knight JA, Rezuke WN, Gillies CG et al (1988) Pulmonary histopathology of rats following parenteral injections of nickel chloride. Toxicol Pathol 16:350-359

15. Sunderman FW Jr, Hopfer SM, Lin S-M et al (1989) Toxicity to alveolar macrophages in rats following parenteral injection of nickel chloride. Toxicol Appl Pharmacol 100:107-118

16. Kosboth M, Chin-Loy A, Lyons R, Wesson SK, Reeves WH (2007) Malar rash caused by metal allergy in a patient with systemic lupus erythematosus. Nat Clin Pract Rheumatol 3:240-245

17. Hostynek JJ (2002) Nickel-induced hypersensitivity: etiology, immune reactions, prevention and therapy. Arch Dermatol 294(6):249-267

18. Jensen ChS, Menné T, Lisby S, Kristiansen J, Veien NK (2003) Experimental systemic contact dermatitis from nickel: a doseresponse study. Contact Dermatitis 49:124-132

19. Cazzato IA, Vadrucci E, Cammarota G, Minelli M, Gasbarrini A (2011) Lactose intolerance in systemic nickel allergy syndrome. Int J Immunopathol Pharmacol 24:535-537

20. Fukahara K, Minami K, Reiss N, Fassbender D, Koerfer R (2003) Systemic allergic reaction to the percutaneous patent foramen ovale occluder. J Thorac Cardiovasc Surg 125:213-214

21. Moed H, Boorsma DM, Stoof TJ et al (2004) Nickel-responding $\mathrm{T}$ cells are $\mathrm{CD}^{+}{ }^{+} \mathrm{CLA}^{+} \mathrm{CD}^{+} 5 \mathrm{RO}^{+}$and express chemoquine receptors CXCR3, CCR4 and CCR10. Br J Dermatol 151:32-41

22. McFadden JP, Dearman RJ, White JML et al (2011) The HaptenAtopy hypothesis II: the 'cutaneous hapten paradox'. Clin Exp Allergy 41:327-337

23. Schnuch A, Westphal G, Mossner R, Uter W, Reich K (2011) Genetic factors in contact allergy-review and future goals. Contact Dermatitis 64:2-23

24. Thyssen JP, Linneberg A, Menné T, Johansen JD (2007) The epidemiology of contact allergy in the general populationprevalence and main findings. Contact Dermatitis 57:287-299

25. Gherardi R, Authier F (2012) Macrophagic myofasciitis: characterization and pathophysiology. Lupus 21(2):184-189

26. Patil SU, Long A (2012) Nickel hypersensitivity and coronary artery stents. In: Basow DS (ed) UpToDate. UpToDate, Waltham

27. Thyssen JP, Johansen JD et al (2009) Nickel allergy in Danish women before and after nickel regulation. $\mathrm{N}$ Engl $\mathrm{J}$ Med 360:2259-2260 